\title{
Migraine and tension type headache in adolescents at grammar school in Germany - burden of disease and health care utilization
}

\author{
Lucia Albers $^{1 *}$, Andreas Straube ${ }^{2}$, Mirjam N Landgraf ${ }^{3}$, Filipp Filippopulos ${ }^{2}$, Florian Heinen ${ }^{3}$ and Rüdiger von Kries ${ }^{1}$
}

\begin{abstract}
Background: Tension-type headache and migraine are among the most prevalent chronic disorders in children/ adolescents. Data on health care utilization for headache in this age group, however, are sparse.

Methods: In 1399 grammar school students (aged 12-19 years) with headache in the last six months in Germany a) the burden of disease for headache (mean intensity, mean frequency in the last three months and PedMIDAS means), b) medical care utilization defined by proportion of students consulting a physician in the last 12 months and/or taking analgetic drugs in the last three months by headache types (migraine and tension-type headache) and by burden of disease were assessed.

Results: Primary headache substantially impaired daily living activities in adolescents which was mainly related to migraine. Medical care utilization and drug use, however, was low (consulting a physician: 12.0 \%, $95 \%-\mathrm{Cl}=[10.3-13.8]$; taking analgetic drugs: $29.9 \%, 95 \%-\mathrm{Cl}=$ [27.5-32.4]) - even among students with severe headache (physician consultation: $<35 \%$; taking analgetic drugs: $<63 \%$ ). Two thirds of students with any headache and $40 \%$ of those with migraine had neither seen a physician nor used analgetic drugs because of their headache in the preceding 12 months.
\end{abstract}

Conclusions: Adolescents with headache might too rarely seek professional help for treatment of headache. Health promotion in adolescents should increase awareness for evidence-based treatment options for headache.

Keywords: Headache; Children; Adolescents; Health care; Burden of disease

\section{Background}

Tension-type headache (TTH) and migraine are two of the most prevalent disorders in the world [1]. Migraine is the health disorder with the seventh highest impact on the quality of life and society [2]. Estimates on the prevalence and burden of disease for headache in children and adolescents vary considerably depending on age, setting, assessment etc. [3]. A recent review covering 64 headache and migraine studies in children and adolescents of the past 25 years reported an overall mean prevalence of $54.4 \%$ for any headache and $9.1 \%$ for migraine [4]. In the age group of 12 to 15 year old adolescents another review found a prevalence of 66 to

\footnotetext{
*Correspondence: lucia.albers@med.uni-muenchen.de

'Institute of Social Paediatrics and Adolescents Medicine, Division of Epidemiology, Ludwig-Maximilians-University Munich, 80337 Munich, Germany

Full list of author information is available at the end of the article
}

$71 \%$ for at least one headache episode in the last three months, and 33 to $40 \%$ for weekly headaches [5].

The burden of disease for headache in adolescents and children with respect to the impact on social functioning and quality of life is difficult to assess. A review on the impact of headache in children and adolescents stressed very inconsistent and poorly validated impact measures in most of the included studies [3]. Two important domains determining the impact of headache are suggested in this review: 1. Health status of the adolescents in terms of symptoms and illness control; 2. Functional status capturing the ability to perform activities that are essential to meet basic needs, fulfill roles and maintain well-being. In our study we assessed health status by headache frequency and pain intensity. The functional status was measured by the validated PedMIDAS questionnaire (Pediatric Migraine Disability Assessment Score) which assesses the impact of headache related to 
the quality of life in terms of the number of days in the last three months on which headache had a total or partial impact on schools or home life.

Optimal health care should allow coping with the challenges of headache with respect to participation in daily life and quality of life.

In adult populations medical care utilization in terms of consulting a physician and medication use is well evaluated [6-11]. For children and adolescents however, there are currently only very few data available which often date back at least one decade. There is only one study from Germany, which is more than nine years old [12]. From other countries there are two also older studies on health care utilization in adolescents in the United States $[13,14]$. There is only one recent study from Italy in younger children (aged 3 to 11 years) [15].

The aim of our study is to provide an updated assessment of a) the burden of disease for headache in grammar school students aged 12 to 19 years (both as an assessment of health status and functional status of the adolescents), b) medical care utilization of adolescents with headache in Germany defined by consulting a physician and/or taking analgetic drugs by headache types (migraine and TTH) and severity of disease.

\section{Methods}

\section{Study population}

1674 students of the $8^{\text {th }}$ to $10^{\text {th }}$ grade of 12 grammar schools in greater Munich (Germany) recruited for a headache intervention study (reported elsewhere [16]) filled in questionnaires about headache and risk factors for headache including questions concerning the burden of disease for headache and use of medical care and analgetic drugs. 1399 of these students, who reported at least one headache episode in the last six months, were included for this analysis.

\section{Assessment of headache, burden of disease, medical care and use of analgetic drugs}

Headache was assessed by the question "Did you experience headache?", which could be answered with "yes, in the last seven days", "yes in the last three months", "yes, in the last six months", "yes, in the last 12 months" or "no". Students, who reported headache in the last seven days, three or six months were assumed to suffer from headache. Students, who ticked "yes" were asked further questions assessing characteristics for classifying the headache as migraine and TTH (both confirmed and probable diagnosis) according to the International Classification of Headache Disorder-III beta (ICHD-III beta) [17]. A validated pain questionnaire for children and adolescents was used and specific questions were added to further classify headache subtypes as migraine or tension-type headache (TTH) according the classification of the International Headache Society $[18,19]$. Individuals with both probable migraine and probable TTH criteria were given a combined diagnosis of migraine plus TTH. All subjects with headache that did not match any of these criteria for primary headache were considered to have miscellaneous headache (MiscH).

The burden of disease for headache was assessed by the following two aspects: 1) Health status of the adolescents measured by the number of headache days in the last three months and the average pain intensity; pain intensity could be ticked on a Likert scale from $1=$ "very mild" to $10=$ "very severe". 2) The functional status: disability due to headache was assessed using PedMIDAS, a standardized questionnaire consisting of the following six questions about how much headache is affecting dayto-day activity in the last three months [20]: (Q1), How many full days of school were missed in the last three months due to headaches?", (Q2) "How many partial days of school were missed in the last three months due to headaches (do not include full days counted in the first question)?", (Q3) "How many days in the last three months did you function at less than half of your ability in school because of headache (do not include days counted in the first two questions)?", (Q4) "How many days were you not able to do things at home (i.e., chores, homework, etc.) due to headache?", (Q5) "How many days did you not participate in other activities due to headaches (i.e., play, go out, sports, etc.)?", (Q6) "How many days did you participate in these activities, but functioned at less than half your ability (do not include days counted in the 5th question)?". The PedMIDAS total score sums up the number of days reported in each of the questions. Disability grading scores were determined by Hershey et al. based on the PedMIDAS total score [21] with total scores of 0 10 as "little to no disability", 11-30 as "mild disability", 31-50 as "moderate disability", and total scores higher than 50 as "severe disability". PedMIDAS was shown to be a sensitive, reliable and valid assessment instrument for headache related disability in children and adolescents [20].

Usage of analgetic drugs was assessed by the question "How often in the last three months have you taken analgetic drugs to treat your headache?" which could be answered with "never", "rarely", "sometimes", "nearly every time" or "every time". Use of analgetic drugs was assumed if students reported to take at least sometimes analgetic drugs. Furthermore students were asked if they have seen a physician because of their headache in the last 12 months, which could be answered with "yes" or "no".

\section{Statistical analysis}

For estimating the burden of disease for headache means with $95 \%$ confidence intervals (95\%-CIs) were calculated 
for each of the PedMIDAS questions, the PedMIDAS total score, the pain intensity and the number of headache days in the last three months. To assess the headache type specific burden for migraine and TTH, means (with $95 \%$ CIs) were also given for students with a confirmed diagnosis of migraine and TTH (all other students including those with probable diagnosis of migraine or TTH were summarized as other headache types).

Group comparisons were made by comparing means or proportions and the respective binomial $95 \%$-CIs or formal chi-square test statistics. A sensitivity analysis was performed for different definitions of use of analgetic drugs: use of any analgetic drugs as compared to at least sometimes or regular. To assess if patients rather search sleep instead of taking drugs spearmen test and correlation coefficient between drug consumption and seeking sleep for pain relief was calculated.

\section{Results}

Table 1 shows some demographic characteristics and the proportions of headache types in the study population: there was a slight female predominance; the mean age of the students was 14.5 years; the proportions of students in each grade were rather similar; regarding the headache types similar numbers of students with migraine and TTH were observed, however, confirmed diagnosis was more common for migraine than for TTH in our study sample. The mean time period since first onset of headache was about four years. In total only 17 students reported to have headache since less than one year.

Based on the disability grades of the PedMIDAS (Table 2) about $7 \%$ of the students with any headache, $20 \%$ with migraine and only $2 \%$ with TTH were moderately to severely affected by their headache.

The impact of headache on social activities assessed by the PedMIDAS questions is shown in Table 3: The

Table 1 Demographic characteristics of the study population

\begin{tabular}{lll}
\hline Age (in years) -mean (SD) & $14.51(1.09)$ \\
\hline Gender (female) - \% (N) & & $56.94(796)$ \\
Grade - \% (N) & $8^{\text {th }}$ & $32.59(456)$ \\
& $9^{\text {th }}$ & $38.96(545)$ \\
& $10^{\text {th }}$ & $28.45(398)$ \\
Headache types & Confirmed migraine & $18.73(262)$ \\
& Probable migraine & $10.86(152)$ \\
& Confirmed TTH & $9.86(138)$ \\
& Probable TTH & $19.16(268)$ \\
& Migraine + TTH & $23.09(323)$ \\
& MiscH & $18.30(256)$ \\
Time period since the first headache & $4.18(3.01)$ \\
attack (in years) - mean (SD) & \\
\hline
\end{tabular}

Table 2 Proportions of students in the PedMIDAS Disability Grades

\begin{tabular}{|c|c|c|c|c|}
\hline & \multicolumn{4}{|c|}{ PedMIDAS Disability Grades } \\
\hline & Little to none & Mild & Moderate & Severe \\
\hline & $(0-10)$ & $(11-30)$ & $(31-50)$ & $(>50)$ \\
\hline & $\%(\mathrm{~N})$ & & & \\
\hline Any headache & 73.86 & 19.24 & 4.99 & 1.91 \\
\hline$N=1399$ & $(1006)$ & (262) & (68) & (26) \\
\hline \multicolumn{5}{|l|}{ Headache Types: } \\
\hline Migraine & 48.45 & 31.78 & 13.18 & 6.59 \\
\hline$N=262$ & (125) & (82) & (34) & (17) \\
\hline TTH & 83.33 & 14.49 & 2.17 & 0 \\
\hline$N=138$ & (115) & (20) & (3) & (0) \\
\hline \multirow{2}{*}{$\begin{array}{l}\text { Other headache } \\
\text { types } N=999\end{array}$} & 79.30 & 16.56 & 3.21 & 0.93 \\
\hline & (766) & $(160)$ & (31) & (9) \\
\hline
\end{tabular}

number of total/partial absent days from school and of school days on which students were considerably restricted in paying attention in class because of their headache was on average 4.4 days in three months for students with any headache. Pain intensity was on average 5.5 points indicating a moderate pain intensity on average. The pain intensity differed between migraine and TTH patients (6.5/10 versus $4.9 / 10)$.

The average frequency of headache episodes was about nine days in the last three months for all students who had at least one headache episode in the last six months. A higher number of headache days was observed in migraine. Students suffering from migraine reported on average about 10 days with severe restrictions in school attendance in the last three months (absent days or $>50 \%$ restricted abilities to attend class). Health care utilization for headache assessed as seeing a physician in the last 12 months and use of analgetic drugs was low: $12.0 \%$ (95\%-CI = [10.3-13.8]) of the students with headache have seen a physician and $29.9 \%(95 \%-\mathrm{CI}=[27.5-32.4])$ reported to take analgetic drugs. In migraine patients medical care use was higher: $24.4 \%(95 \%-\mathrm{CI}=$ [19.3-30.1]) of migraine patients have seen a physician and $50.8 \%$ (95\%$\mathrm{CI}=[44.5-56.0])$ took analgetic drugs.

Students who reported to take analgetic drugs never or only rarely, did not report to seek sleep more frequently instead - rather the opposite was observed: increasing use of analgetic drugs was positively associated with an incremental seeking of sleep for headache relief $(\mathrm{r}=0.09, \mathrm{p}=0.0005)$.

Among the students with headache having seen a physician $49 \%$ reported using analgetic drugs for management of acute headache episodes compared to $27 \%$ of students not having consulted a physician $(\mathrm{p}<0.001)$. $63.8 \%$ of the students with any headache have neither seen a physician in the last 12 months nor took drugs. 
Table 3 Burden of disease in adolescents with headache

\begin{tabular}{|c|c|c|c|c|c|c|c|c|c|}
\hline & \multicolumn{7}{|c|}{ PedMIDAS (given as number of days in the last three month) } & \multirow{2}{*}{$\begin{array}{l}\text { Pain intensity } \\
(1=\text { "very mild" } \\
\text { to } 10=\text { "very } \\
\text { severe") }\end{array}$} & \multirow{2}{*}{$\begin{array}{l}\text { Number of } \\
\text { headache } \\
\text { days in the last } \\
\text { three months }\end{array}$} \\
\hline & $\begin{array}{l}\text { Q1: absent days } \\
\text { from school }\end{array}$ & $\begin{array}{l}\text { Q2: partial } \\
\text { absent days } \\
\text { from school }\end{array}$ & $\begin{array}{l}\text { Q3: school days } \\
\text { with functioning } \\
<50 \% \text { of their } \\
\text { abilities }\end{array}$ & $\begin{array}{l}\text { Q4: days where } \\
\text { home activities } \\
\text { could not be done }\end{array}$ & $\begin{array}{l}\text { Q5: absent days } \\
\text { from leisure } \\
\text { activities }\end{array}$ & $\begin{array}{l}\text { Q6: days with } \\
\text { functioning }<50 \% \\
\text { of their abilities in } \\
\text { leisure activities }\end{array}$ & $\begin{array}{l}\text { Total score } \\
(\mathrm{Q} 1+\mathrm{Q} 2 \\
+\mathrm{Q} 3+\mathrm{Q} 4+ \\
\mathrm{Q} 5+\mathrm{Q} 6)\end{array}$ & & \\
\hline & \multicolumn{9}{|l|}{ Mean $[95 \%-\mathrm{Cl}]$} \\
\hline \multirow{2}{*}{$\begin{array}{l}\text { Any headache } \\
N=1399\end{array}$} & 0.57 & 0.90 & 3.17 & 1.81 & 1.64 & 1.76 & 9.33 & 5.33 & 8.56 \\
\hline & {$[0.50-0.65]$} & {$[0.77-1.03]$} & {$[2.85-3.49]$} & {$[1.61-2.01]$} & {$[1.49-1.79]$} & {$[1.56-1.96]$} & {$[8.61-10.05]$} & {$[5.30-5.37]$} & {$[8.35-8.78]$} \\
\hline \multicolumn{10}{|l|}{ Headache Types: } \\
\hline \multirow[t]{2}{*}{ Migraine $N=262$} & 1.08 & 1.82 & 6.67 & 4.33 & 3.46 & 3.50 & 19.19 & 6.51 & 13.06 \\
\hline & {$[0.88-1.29]$} & {$[1.35-2.29]$} & [5.46-7.89] & {$[3.49-5.16]$} & {$[2.93-4.00]$} & {$[2.70-4.30]$} & [16.45-21.93] & {$[6.44-6.57]$} & [12.38-13.73] \\
\hline \multirow[t]{2}{*}{ TTH N = 138} & 0.44 & 0.66 & 2.05 & 1.09 & 0.98 & 1.00 & 5.92 & 4.94 & 8.83 \\
\hline & {$[0.25-0.63]$} & {$[0.42-0.91]$} & [1.61-2.49] & [0.78-1.41] & [0.64-1.32] & {$[0.75-1.26]$} & [4.78-6.97] & [4.85-5.03] & [8.27-9.39] \\
\hline \multirow{2}{*}{$\begin{array}{l}\text { Other headache } \\
\text { types } N=999\end{array}$} & 0.46 & 0.69 & 2.43 & 1.27 & 1.26 & 1.41 & 7.18 & 5.08 & 7.34 \\
\hline & {$[0.37-0.54]$} & {$[0.56-0.82]$} & {$[2.14-2.73]$} & [1.11-1.43] & [1.12-1.39] & {$[1.23-1.59]$} & {$[6.56-7.80]$} & [5.04-5.12] & [7.11-7.46] \\
\hline
\end{tabular}


Among migraine patients $66.7 \%$ of the students having consulted a physician reported to take analgetic drugs compared to $45.6 \%$ of the students not having seen a physician ( $p<0.005) .41 .0 \%$ of the migraine patients neither have seen a physician nor took analgetic drugs.

Irrespective of how the burden of disease was classified (PedMIDAS total scale $>30$, pain intensity $>5$ or frequency of more than 6 days of headache in the last three months), use of health care appeared to be low in general. Even in the more severe categories health care use did not exceed $60 \%$ (physician consultation: 19 to $35 \%$; use of analgetic drugs: 19 to $28 \%$ ) (Table 4). As shown in a sensitivity analysis (Additional file 1: Table S1) defining use of analgetic drugs as "any use of analgetic drugs" instead of counting rare use of analgetic drugs as no use shifted these proportions about $20 \%$ higher irrespective of the burden of disease due to headache observed.

The PedMIDAS scores for students who consulted and students who did not consult a physician in the last year is shown in Additional file 2: Figure S1 of the supplemental material: Students who consulted a physician because of their headaches were more likely to have "mild", "moderate" or "severe" than "mild to none" PedMIDAS scores compared to students who did not consult a physician.

\section{Discussion}

The impact of headache, especially migraine in adolescents was substantial accounting for considerable inability to attend school. However, medical care utilization was low - even among student with severe headache. Two thirds of students with any headache and $40 \%$ of those with migraine had neither seen a physician in the preceding 12 months nor used analgetic drugs in the preceding three months.

The high burden of disease in children and adolescents with headache is in line with two previous reviews $[3,4]$. Three studies cited in these reviews assessed the burden of migraine by PedMIDAS and reported total scores of 17.8 to 44 days where children/adolescents were totally or partially disabled at home or at school because of migraine [20-22]. However, these studies were conducted in a clinical sample which could explain the higher number of days of impairment in two of these studies. Two other population based studies reported that students missed on average 7.2 school days in the last six months due to migraine, which is comparable to our study (about 3 days in the last 3 months) [23,24].

For children and adolescents data for headache health care utilization are sparse. Most studies date back to at least one decade. There is only one recent study from

Table 4 Frequency of medical care utilization by burden of disease for headache

\begin{tabular}{|c|c|c|c|}
\hline & & $\begin{array}{l}\text { Having seen a physician because of the } \\
\text { headache in the last } 12 \text { months (yes) }\end{array}$ & $\begin{array}{l}\text { Use of analgetic drugs } \\
\text { (sometimes or every time) }\end{array}$ \\
\hline \multirow[t]{3}{*}{ Burden of disease } & & $\%$ & \\
\hline & & $(\mathrm{N})$ & \\
\hline & & [95 \%-Cl] & \\
\hline \multirow[t]{6}{*}{ PedMIDAS } & \multirow{3}{*}{$\begin{array}{l}\text { moderate/severe }(\mathrm{N}=93) \\
\text { (total scale }>30)\end{array}$} & 35.48 & 62.77 \\
\hline & & (33) & (59) \\
\hline & & [25.83-46.09] & [52.18-72.52] \\
\hline & \multirow{3}{*}{$\begin{array}{l}\text { little to none/mild ( } N=1259 \text { ) } \\
\text { (total scale } \leq 30 \text { ) }\end{array}$} & 10.25 & 27.61 \\
\hline & & (129) & (349) \\
\hline & & [08.63-12.05] & [25.16-30.17] \\
\hline \multirow{6}{*}{$\begin{array}{l}\text { Pain intensity (on Likert } \\
\text { scale from } 1 \text { to 10) }\end{array}$} & \multirow[t]{3}{*}{$>5(\mathrm{~N}=625)$} & 20.00 & 43.06 \\
\hline & & (125) & (270) \\
\hline & & [16.93-23.35] & [39.15-47.04] \\
\hline & \multirow[t]{3}{*}{$\leq 5(N=740)$} & 4.73 & 19.05 \\
\hline & & (35) & (141) \\
\hline & & [3.32-6.52] & [16.28-22.07] \\
\hline \multirow{6}{*}{$\begin{array}{l}\text { Frequency of headache } \\
\text { episodes }\end{array}$} & \multirow{3}{*}{$\begin{array}{l}\text { More than six headache days in } \\
\text { the last three month }(\mathrm{N}=529)\end{array}$} & 18.71 & 40.23 \\
\hline & & (99) & (214) \\
\hline & & [15.48-22.30] & [36.03-44.53] \\
\hline & \multirow{3}{*}{$\begin{array}{l}\text { At most } 6 \text { headache days in the last } \\
\text { three months }(N=858)\end{array}$} & 7.81 & 23.48 \\
\hline & & (67) & (201) \\
\hline & & [6.10-9.81] & [20.68-26.47] \\
\hline
\end{tabular}


Italy on medication use in pre pubertal children [15]. In a 9 year old German study (12) use of analgetic drugs and physician consultation were compared in several disorders (stomach-, back-, orofacial pain) including headache (analgetic drugs use $<25 \%$, physician consultation $\leq 17 \%)$. No differentiation by type of headache is reported in this study.

A strength of our study and a new aspect is the analysis of actual data for health care utilization of adolescents with headache in Germany in relation to type and severity of headache. Furthermore, since the study was done in an area with general high availability of health care the low consultation rate seems to reflect the students' unawareness of the benefit of medical consultation regarding their headaches rather than lack of treatment facilities. Headache type specific estimates were confined to categories previously shown to be stable such as confirmed migraine and TTH [25]. A further strength of our study is that the burden of disease for headache was assessed by two domains: The disability due to headache using an age-adapted, validated and reliable instrument (PedMIDAS), and additional the functioning level by considering pain intensity and frequency of headache of the adolescents [20]. This is important since the retrospective assessment by PedMIDAS may be fraught with bias in both directions: 1 . Underestimation for non-school days due to headache on weekend days was shown [26]. 2. Due to the retrospective assessment of the PedMIDAS, recall bias might be possible; it has been shown, that the recall of the disability due to headache in the last three months overestimates the exact number of days compared to a headache diary [27]. A further limitation could be the failure to assess distress due to headache and quality of life directly by including a general quality of life measure (like i.e. KINDL) in our questionnaire [28]. However, in a former study in grammar school students in Munich strong restriction of the quality of life by headache, especially migraine has been shown [29]. Another measure for the burden of headache could have been the duration of the headache episodes, which unfortunately was only assessed by categories precluding calculation of mean values for simple assessment of the burden for any headache/headache types. Another weakness of the study pertains to the failure to ask for prophylactic therapy in our questionnaire and the specific analgetic drugs which were used to treat the acute headache attacks. However, prophylactic medications have to be prescribed by a physician and the number of patients consulting a physician was rather low. Thus missed prophylactic drug treatment is unlikely to be high in our sample.

Ascertainment of physicians' visits in the last year only might be an underestimate. Questions about lifetime consultations because of headache as well as about the course of headache (unchanged, improved, deteriorated) during the previous year as compared to the year before may have been useful, but unfortunately was not assessed in our study. Furthermore emergence of headache might have been too recent to allow for a doctor's visit. As only 17 students reported to have headache since less than one year, however, it seems very unlikely that students did not consult a doctor in the last year because the time since onset of headache was too short for making an appointment.

A further source of bias could be problems in understanding the difference between analgetic drugs and prescription medication in the students. However, analgetic drug in German means any drug used for pain relief irrespective of whether the drug is prescribed or OTC and therefore this seems rather unlikely.

Limited external validity is a weakness of this paper since the study was performed in grammar school students in an urban environment. However, since grammar school students usually have a higher socioeconomic family background, it is likely that access to health care in less privileged children with headache is even lower.

\section{Conclusion}

Adolescents in Germany with primary headaches, specifically migraine, have a high burden of disease. Although health care utilization is higher in migraineurs (particularly among those more severely affected) than for other types of headache, almost $40 \%$ of the students with migraine had neither seen a physician during the previous 12 months nor reported medical treatment. Health care promotion in adolescents should include elements to increase awareness for treatment options for headache.

\section{Additional files}

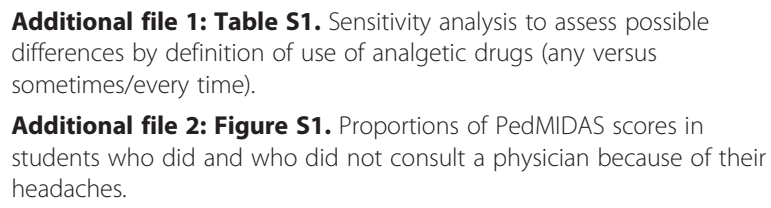

Additional file 2: Figure S1. Proportions of PedMIDAS scores in students who did and who did not consult a physician because of their headaches.

\section{Abbreviations}

TTH: Tension-type headache; Cl: Confidence interval; ICHD: International classification of headache disorder.

\section{Competing interests}

The authors declare that they have no competing interests.

\section{Authors' contributions}

LA carried out the initial analyses, drafted the initial manuscript, and approved the final manuscript as submitted. AS, MNL, FF, FH, RvK conceptualized and designed the study, revised the manuscript and approved the final manuscript as submitted. 


\section{Acknowledgements}

We would like to thank all participating students and teachers and the Bavarian ministry of education for giving the opportunity to perform this study. We also thank the DMKG (German Headache Society) which supported the study by an unrestricted fund and the German Center for Vertigo and Balance Disorders which partly funded LA.

\section{Author details}

${ }^{1}$ Institute of Social Paediatrics and Adolescents Medicine, Division of Epidemiology, Ludwig-Maximilians-University Munich, 80337 Munich, Germany. ${ }^{2}$ Department of Neurology, Ludwig-Maximilians-University Munich, 81377 Munich, Germany. ${ }^{3}$ Department of Paediatric Neurology and Developmental Medicine, Hauner Children's Hospital,

Ludwig-Maximilians-University Munich, 80337 Munich, Germany.

Received: 2 April 2015 Accepted: 25 May 2015

Published online: 04 June 2015

\section{References}

1. Murray CJL, Vos T, Lozano R, et al. (2012) Disability-adjusted life years (DALYs) for 291 diseases and injuries in 21 regions, 1990-2010: a systematic analysis for the Global Burden of Disease Study 2010. Lancet 380:2197-2223. doi: 10.1016/S0140-6736(12)61689-4

2. Vos T, Flaxman AD, Naghavi M, et al. (2012) Years lived with disability (YLDs) for 1160 sequelae of 289 diseases and injuries 1990-2010: a systematic analysis for the Global Burden of Disease Study 2010. Lancet 380:2163-2196. doi: 10.1016/S0140-6736(12)61729-2

3. Kernick D, Campbell J (2009) Measuring the impact of headache in children: a critical review of the literature. Cephalalgia Int J Headache 29:3-16. doi:10.1111/j.1468-2982.2008.01693.x

4. Wöber-Bingöl C (2013) Epidemiology of migraine and headache in children and adolescents. Curr Pain Headache Rep 17:341. doi:10.1007/s11916-0130341-z

5. Straube A, Heinen F, Ebinger F, von Kries R (2013) Headache in school children: prevalence and risk factors. Dtsch Ärztebl Int 110:811-818. doi:10.3238/arztebl.2013.0811

6. Hughes MD, Wu J, Williams TC et al (2013) The experience of headaches in health care workers: opportunity for care improvement. Headache 53:962-969. doi:10.1111/head.12069

7. Minen MT, Seng EK, Holroyd KA (2014) Influence of family psychiatric and headache history on migraine-related health care utilization. Headache 54:485-492. doi:10.1111/head.12300

8. Liu R, Yu S, He M et al (2013) Health-care utilization for primary headache disorders in China: a population-based door-to-door survey. J Headache Pain 14:47. doi:10.1186/1129-2377-14-47

9. Abdo SA, Amood Al-Kamarany M, Alzoubi KH et al (2014) Primary headache in yemen: prevalence and common medications used. Neurol Res Int 2014:808126. doi:10.1155/2014/808126

10. Radtke A, Neuhauser H (2012) Low rate of self-awareness and medical recognition of migraine in Germany. Cephalalgia Int J Headache 32:1023-1030. doi:10.1177/0333102412454945

11. Mehuys E, Paemeleire K, Van Hees T et al (2012) Self-medication of regular headache: a community pharmacy-based survey. Eur J Neurol Off J Eur Fed Neurol Soc 19:1093-1099. doi:10.1111/j.1468-1331.2012.03681.x

12. Hirsch C, John MT, Schaller H-G (1985) Türp JC (2006) Pain-related impairment and health care utilization in children and adolescents: a comparison of orofacial pain with abdominal pain, back pain, and headache. Quintessence Int Berl Ger 37:381-390

13. Strine TW, Okoro CA, McGuire LC, Balluz LS (2006) The associations among childhood headaches, emotional and behavioral difficulties, and health care use. Pediatrics 117:1728-1735. doi:10.1542/peds.2005-1024

14. Lewis DW, Diamond S, Scott D, Jones V (2004) Prophylactic treatment of pediatric migraine. Headache 44:230-237

15. Cavestro C, Montrucchio F, Benci P et al (2014) Headache prevalence and related symptoms, family history, and treatment habits in a representative population of children in Alba, Italy. Pediatr Neurol 51:348-353. doi:10.1016/ j.pediatrneurol.2014.05.022

16. Albers $L$, Heinen F, Landgraf $M$ et al (2014) Headache cessation by an educational intervention in grammar schools: a cluster randomized trial. Eur J Neurol Off J Eur Fed Neurol Soc. doi:10.1111/ene.12558
17. Headache Classification Committee of the International Headache Society (IHS) (2013) The International Classification of Headache Disorders, 3rd edition (beta version). Cephalalgia Int J Headache 33:629-808. doi:10.1177/ 0333102413485658

18. Fendrich K, Vennemann M, Pfaffenrath V et al (2007) Headache prevalence among adolescents-the German DMKG headache study. Cephalalgia Int J Headache 27:347-354. doi:10.1111/j.1468-2982.2007.01289.x

19. Milde-Busch A, Blaschek A, Borggrafe I, et al. (2010) Associations of diet and lifestyle with headache in high-school students: results from a crosssectional study. Headache 50:1104-14. doi: HED1706 10.1111/j.15264610.2010.01706.x

20. Hershey AD, Powers SW, Vockell AL et al (2001) PedMIDAS: development of a questionnaire to assess disability of migraines in children. Neurology 57:2034-2039

21. Hershey AD, Powers SW, Vockell A-LB et al (2004) Development of a patient-based grading scale for PedMIDAS. Cephalalgia Int J Headache 24:844-849. doi:10.1111/j.1468-2982.2004.00757.x

22. D'Amico D, Grazzi L, Usai S et al (2003) Use of the Migraine Disability Assessment Questionnaire in children and adolescents with headache: an Italian pilot study. Headache 43:767-773

23. Hartmaier SL, DeMuro-Mercon C, Linder S et al (2001) Development of a brief 24-hour adolescent migraine functioning questionnaire. Headache 41:150-156

24. Smith MS, Martin-Herz SP, Womack WM, Marsigan JL (2003) Comparative study of anxiety, depression, somatization, functional disability, and illness attribution in adolescents with chronic fatigue or migraine. Pediatrics 111:e376-381

25. Albers L, Straube A, Landgraf MN et al (2014) High diagnostic stability of confirmed migraine and confirmed tension-type headache according to the ICHD-3 beta in adolescents. J Headache Pain 15:36. doi:10.1186/11292377-15-36

26. Heyer GL, Merison K, Rose SC et al (2014) PedMIDAS-based scoring underestimates migraine disability on non-school days. Headache 54:1048-1053. doi:10.1111/head.12327

27. Heyer GL, Perkins SQ, Rose SC et al (2014) Comparing patient and parent recall of 90-day and 30-day migraine disability using elements of the PedMIDAS and an Internet headache diary. Cephalalgia Int J Headache 34:298-306. doi:10.1177/0333102413508240

28. Kröner-Herwig B, Heinrich M, Vath N (2010) The assessment of disability in children and adolescents with headache: adopting PedMIDAS in an epidemiological study. Eur J Pain Lond Engl 14:951-958. doi:10.1016/ j.ejpain.2010.02.010

29. Milde-Busch A, Heinrich S, Thomas S et al (2010) Quality of life in adolescents with headache: results from a population-based survey. Cephalalgia Int J Headache 30:713-721. doi:10.1177/0333102409354389

\section{Submit your manuscript to a SpringerOpen ${ }^{\odot}$ journal and benefit from:}

- Convenient online submission

- Rigorous peer review

- Immediate publication on acceptance

- Open access: articles freely available online

- High visibility within the field

- Retaining the copyright to your article

Submit your next manuscript at $>$ springeropen.com 